International Journal of Physical Sciences and Engineering
Available online at www.sciencescholar.us
Vol. 4 No. 1, April 2019, pages: $1-10$
e-ISSN : 2550-6943, p-ISSN : 2550-6951
https://doi.org/10.29332/ijpse.v4n1.389

\title{
Impact of Distributed Generation in the Electrical System of Ecuador
}

\author{
CrossMark \\ Edison Fabián Sumba Sumba a, Angel Victor Sumba Sumba b, Guillermo Antonio Loor Castillo c, Jesus \\ Alberto Pérez Rodríguez ${ }^{\mathrm{d}}$
}

Manuscript submitted: 09 November 2019, Manuscript revised: 18 December 2019, Accepted for publication: 01 January 2010

Corresponding Author a

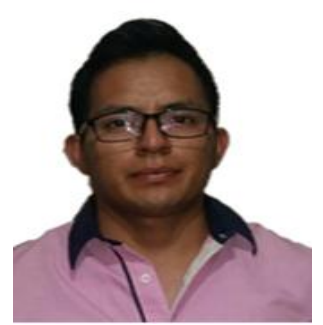

Keywords

benefits;

distributed generation;

electric systems;

power;

renewable energy;

\begin{abstract}
Decentralized generation today assumes a very important role in the stability of electric power, especially in rural areas where electric power supplied by large Power plants, is delivered to points of consumption with a poor quality of energy this due to the distance that is found, from the generation to the final consumer, the implementation of the GD is directly related to the increase in the quality of electric energy as well as providing flexibility to the electrical distribution system. The deployment of distributed generation in electricity distribution networks can potentially increase their reliability and reduce the cost of power, by installing energy sources closer to the demand or consumption points. This type of generation involves a great variety of energy sources, such as; wind, solar, hydraulic, fossil fuels, biomass, among others.
\end{abstract}

International Journal of Physical Sciences and Engineering (C) 2020. This is an open access article under the CC BY-NC-ND license (https://creativecommons.org/licenses/by-nc-nd/4.0/).

\section{Contents}

Abstract

1 Introduction

2 Materials and Methods

3 Results and Discussions

3.1 A well-known definition is that of the IEEE (Institute of Electrical and Electronics Engineers)

3.2 Positive impact of distributed generation

4 Conclusion

Acknowledgments.

a Universidad Técnica De Manabí, Portoviejo, Ecuador

b Universidad Técnica De Manabí, Portoviejo, Ecuador

c Universidad Técnica De Manabí, Portoviejo, Ecuador

d Universidad Técnica De Manabí, Portoviejo, Ecuador 


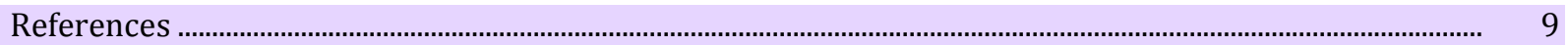

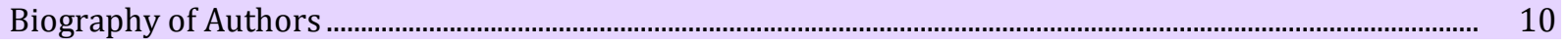

\section{Introduction}

Man assumes energy needs to be able to perform tasks such as moving fast, cooking, building houses, warming, and dressing, among other activities (Correa et al., 2016). After the second industrial revolution, electricity was positioned as one of the most important services for world economic development, due to its ease of transport and especially because it allowed opening a whole spectrum of new inventions and technological solutions previously imagined, for example, the Internet and all its applications, as well as being a clean and harmless energy for health (Flores, 2011). At present, it is known that any method of electricity generation emits a risk of contamination to people's health, such as $\mathrm{CO} 2$.

In the last decade, both in our country and in the rest of the world, issues such as the conservation of natural resources and the protection of the environment have reached great importance. One of the areas of great environmental problems is the generation of energy in this regard, one of the most significant achievements is, without a doubt, the use of renewable energy, also called "green or clean energy", such as wind, solar, Hydraulics, and biomass, which reduce the emissions of gases that cause global warming.

The "Distributed Generation (GD)" is defined as the strategic use of modular power generation units, installed in isolation to provide a specific service, or interconnected to electricity distribution networks in the vicinity of consumption, to reduce the cost of service and improve the quality of energy delivered (Heras, 2005). In the present work an analysis will be made on the impact of the GD, in the electrical sector of Ecuador, it is known that previously in the country the production of electrical energy was not sufficient to supply the demand of the users, with the connections of GD It is possible to supply the required demand from many places that are isolated from a power line.

\section{Materials and Methods}

The analysis of the elements necessary to encourage the use of GD in Ecuador is very efficient because thanks to its connections, $\mathrm{CO} 2$ emissions can be progressively reduced. For that, they used a research technique called System Dynamics (DS). The DS is a methodology that allows the construction of models through a careful analysis of the system elements (Izquierdo, 2008). Dynamics models are constructed through an abstraction process with the objective of facilitating the understanding of certain aspects of a real system.

This analysis makes it possible to extract the internal logic of the model, and thereby try to understand the long-term evolution of the system. System dynamics is a methodology that addresses and integrates the information available and the interactions between the components of a system (Forrester, 1969).

The studies carried out with DS are divided into two phases: the first phase has as a basic objective to get to understand the structural causes that cause the behavior of the system (Gallardo, 2013), this applies to increase the knowledge about the role of each element of the systems that It is part of the system that is about solving. Then, the second phase aims to propose several alternative solutions and, with the help of specialized computer packages, analyze the benefits of each proposal in a long-term environment (Gallardo, 2013).

GD emerges as an important alternative for the provision of electric power service since it can increase the reliability and security of supply in the short to medium and long term (Jiménez, 2012), in the province of Manabí some work has been carried out Research related to this topic. At the Technical University of Manabí (UTM) a photovoltaic system connected directly to the load has been installed with very good results (Vázquez et al., 2018), studies have also been carried out with the aim of improving the quality of energy used distributed generation as an improvement of the electrical system (Rodríguez et al., 2018).

Other research related to the change of the energy matrix, where energy sources can be applied in the mode of distributed generation (Macias et al., 2018). To enhance local development, students have worked with students in projects where they make technical assessments of the advantages of distributed generation in isolated communities and autonomous systems (Vázquez et al., 2019). The objective of the research is to show the positive impacts of the distributed generation that promotes change of energy matrix in Ecuador. 


\section{Results and Discussions}

\subsection{A well-known definition is that of the IEEE (Institute of Electrical and Electronics Engineers)}

"Distributed Generation is the production of electricity with facilities that are small enough in relation to large generation plants, so that they can be connected almost anywhere of an electrical system. It is a set of distributed resources" (IEEE, 2006).

Generally, distributed generation is defined as the generation of electricity by relatively small plants (less than $10 \mathrm{MW}$ ) in relation to centralized plants, with sufficient capacity to allow interconnection at any point of the electrical system considering the following aspects: purpose and location; nominal power and voltage level; characteristics of the energy delivery zone (Muñoz et al., 2017).

\section{Ecuadorian regulatory framework}

In the Ecuadorian case, the Organic Law of Electric Power Public Service does not clearly specify the aspects, so that small photovoltaic enterprise (natural persons), connected to the distribution networks (low voltage), can produce energy for own consumption and surpluses for commercialization through the electricity grid. In this area, the need to contemplate in the law, regulations, regulations, etc., the implementation of distributed generation with non-conventional renewable technologies, especially photovoltaic solar for the residential or domestic sector, is determined by the high energy potential determined by the levels of heatstroke, granting different types of incentives (Barreto, 2014).

Considering Japan and Germany, which established higher rates of the energy injected into the network in relation to the billing price for customer consumption, with the purpose of establishing incentives for a real possibility of saving in the medium and In the long term in the payment of electricity, this TIF incentive system presents less risk to the investor and produces - over the years - the reduction of the incentive (prize) according to the decrease in investment costs of energy technology, differentiating the size of the plant and the geographic location so that it allows to distribute the technology in a homogeneous way. In addition, this TIF regulatory instrument has been widely implemented in Spain and Denmark (Barbosa, 2016). Ecuador until recently applied the policy of preferential prices for non-conventional renewable sources in the production of electricity that could be said to correspond to a Feed-in Tariff system, this incentive was established through Codified Regulation No. CONELEC 001/13, which was repealed in June 2016 (ARCONEL, 2017). In this regulation no price was contemplated for photovoltaic solar energy, noticing a strong deficiency for the incorporation of this type of renewable energy.

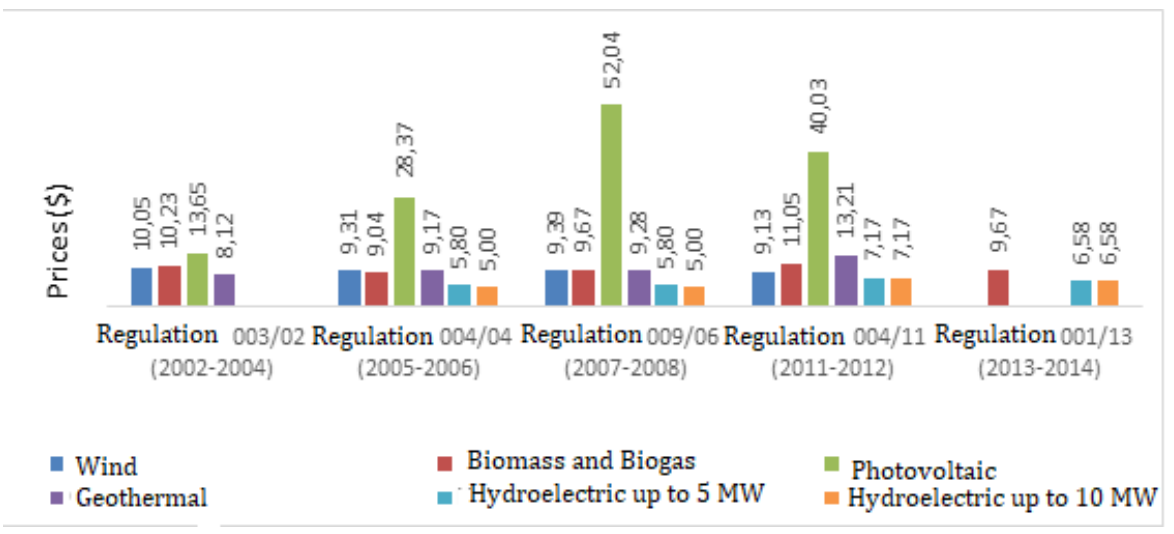

Figure 1. Renewable energy prices in Ecuador

Source: Prepared with information (CONELEC, 2013)

Sumba, E. F. S., Sumba, A. V. S., Castillo, G. A. L., \& Rodríguez, J. A. P. (2020). Impact of distributed generation in the electrical system of Ecuador. International Journal of Physical Sciences and Engineering, 4(1), 1-10. 
Figure 1 shows the evolution of the prices approved by the former CONELEC, in just over a decade, where the highest price for photovoltaic solar energy occurs in 2007 and 2008 (gray bars). Where the institution was still in force, CONELEC was replaced by ARCONEL on January 16, 2015.

\section{Models of distributed microgeneration}

Three business models for distributed photovoltaic are proposed, which are considered two measurement systems applicable: the first called net metering where the net value of energy is determined (difference between the injected into the network and the consumed), and the second known as "Feed-in Tariff" FIT where the energy injected into the network is determined at a special price as an incentive. The cost of the energy produced by a photovoltaic system in Ecuador is USD / $\mathrm{kWh} 0.1342$ with the discount rate of 7\%, the $\mathrm{CF}$ (capacity factor) $=15 \%$, while with the discount rate of $10 \%, \mathrm{CF}=20 \%$ the cost of energy reaches USD / $\mathrm{kWh} 0.1229$, values that do not include the battery bank or land, these values are increasingly competitive in relation to non-conventional renewable sources (Muñoz et al., 2017; Belvinel et al., 2018).

\section{Renewable Energy Sources}

The term "Renewable Energy Source (RES)" (Bayod et al., 2005), refers to the "eternal" Natural Energy Source such as the sun and wind. Renewable Energy Systems convert this source of natural energy into useful energy (electricity and heat). According to the European directive RES-E, renewable energy sources include Power plants that use energy resources for their generation that can be renewed unlimitedly from sun (photovoltaic), wind (wind), water, (small hydroelectric plants), Earth's interior (geothermal), biomass, biogas, waves, tides, hot and dry rocks, the same that, due to their relative recent development and exploitation, have not yet reached a commercialization degree to compete freely with conventional sources, but which, unlike the latter, have a very low environmental impact (CONELEC, 2015).

\section{Electricity generation by type of company.}

Effective power by type of source, in table 1 shows the values of effective power by type of renewable and non-renewable sources.

Table 1

Effective power by type of source

\begin{tabular}{llll}
\hline Effective Power of Generators & & MW & $\%$ \\
\hline Renewable Energy & Hydraulic & $5,036.43$ & 62.58 \\
& Wind & 21.15 & 0.26 \\
& Photovoltaic & 26.74 & 0.33 \\
& Biomass & 136.4 & 1.69 \\
Total Renewable Energy & Biogas & 6,5 & 0.08 \\
Non-Renewable & & $5,227.22$ & 64.95 \\
& Thermal MCI & $1,613.60$ & 20.05 \\
Total Non-Renewable Energy & Thermal Turbo gas & 775.55 & 9.64 \\
Total Effective Power & & 431.74 & 5.36 \\
\hline
\end{tabular}

Source: Prepared with information from (ARCONEL, 2018)

Figure 2 shows the effective power by type of source which was 8,048.11 MW; in the same stands out the majority participation of the hydroelectric plants, with 5,036.43 MW, corresponding to $62.58 \%$, with respect to the total effective power at the national level. On the other hand, there are non-renewable thermal power plants, in which MCIs have the largest share that is 1,613.60 MW, which corresponds to $20.05 \%$ in relation to the national total. 


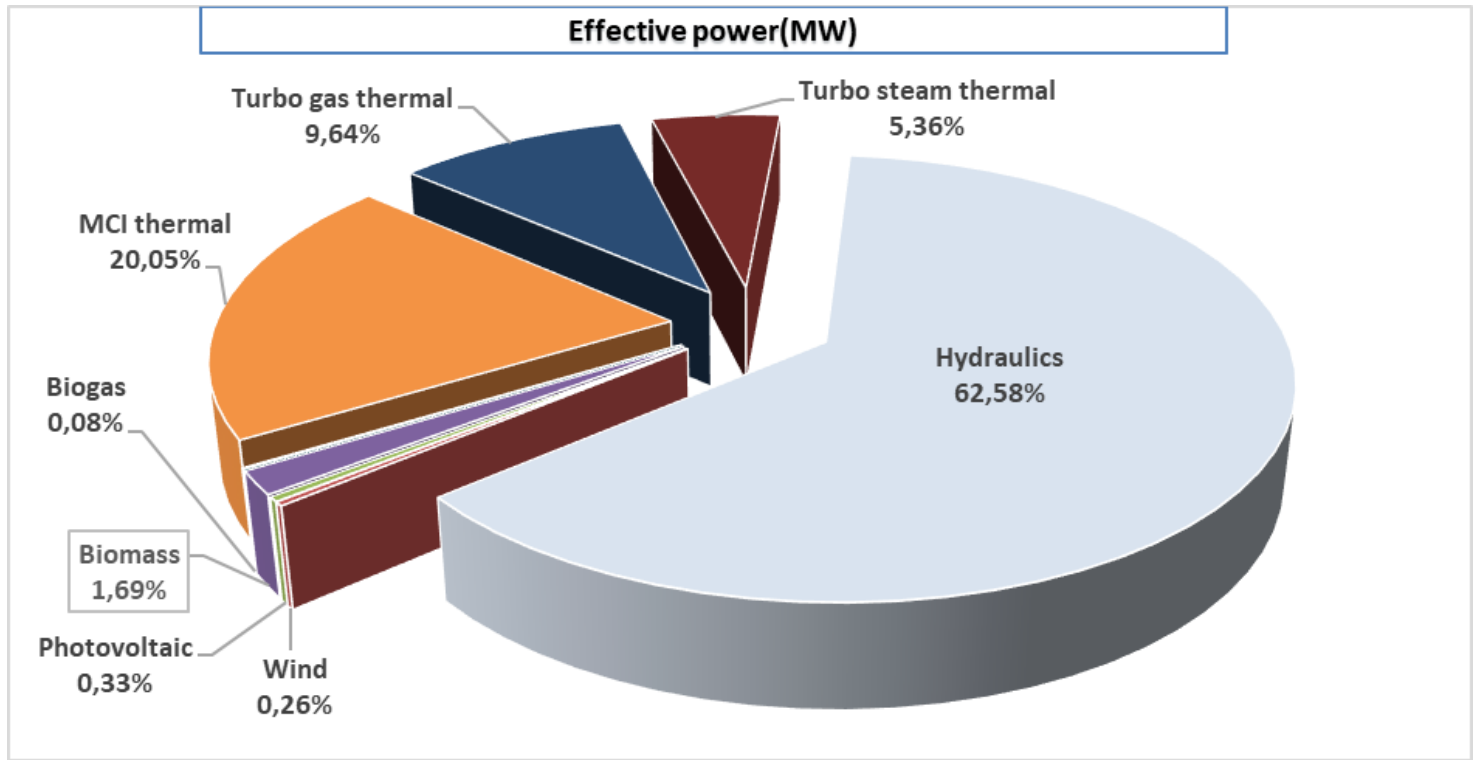

Figure 2. Effective power.

Source: Prepared with information from (ARCONEL, 2018)

The effective power of the distribution generation within the total effective power of 8,048.11 MW, the distribution generation participates with an effective power of 381.39 MW.

Table 2

The effective power of the distributors

\begin{tabular}{ll}
\hline Central type & MW \\
\hline Hydraulic & 140.36 \\
Wind & 4.65 \\
Photovoltaic & 3.17 \\
Thermal MCI & 51.97 \\
Thermal Turbogas & 161 \\
Thermal Turbovapor & 20.24 \\
total distributor & 381.39 \\
\hline \multicolumn{2}{c}{ Source: Prepared with information from (ARCONEL, 2018) }
\end{tabular}

Sumba, E. F. S., Sumba, A. V. S., Castillo, G. A. L., \& Rodríguez, J. A. P. (2020). Impact of distributed generation in the electrical system of Ecuador. International Journal of Physical Sciences and Engineering, 4(1), 1-10. 
Figure 3 shows the effective Power of the distributors of Ecuador

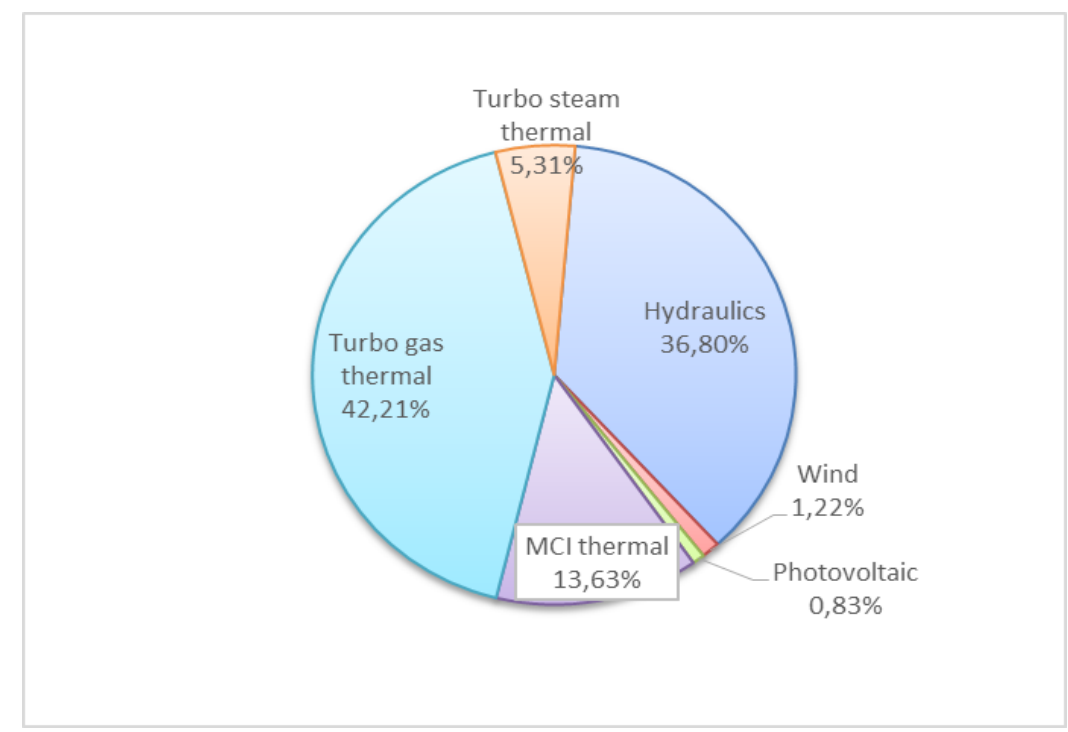

Figure 3. The effective power of the distributors

Source: Prepared with information from (ARCONEL, 2018)

\section{Future of distributed generation}

The liberalization of the electricity market, the increase in costs and the impact of environmental regulations, make the construction of large power plants to meet the increase in demand for electrical energy are economically unviable. As a consequence, it is easy to predict that the DG will have an important role in the electrical power systems of the future. The deployment of the GD in the distribution networks could potentially increase its reliability and lower the cost of power by installing energy sources closer to the demand centers. This type of generation includes a wide variety of energy sources, such as solar, wind, hydraulic, fossil fuels etc. (Heras, 2005).

It is estimated that by 2020, it will be possible for the cost of photovoltaic solar energy to be reduced to the point of becoming a competitive energy source compared to conventional technologies. Concomitantly, policies should be adopted to avoid negative externalities vis-à-vis other types of non-conventional renewable energy (Barbosa, 2016; Mantuano et al., 2019).

\section{Environmental aspects}

Distributed generation contributes favorably to the environment because it is closely linked to renewable energy and other high-efficiency technologies such as cogeneration. Therefore, being linked to renewable energy sources is a key factor in reducing greenhouse gas emissions by reducing the use of fossil fuels (Hugo, 2014).

Studies carried out to determine that of a total of 1 trillion tons of $\mathrm{CO} 2$ released on the planet since the beginning of industrialization, $80 \%$ corresponds to emissions from the last 50 years (Aguilera, 2012). For this reason, increasingly in the world non-conventional renewable energies take preponderance, developing different forms of application as is the case of distributed or embedded generation in electrical distribution systems.

\subsection{Positive impact of distributed generation}

The connection of GD tries to increase the reliability in terms of energy supply, this is made possible because the GD are sources of energy that are close to the consumption centers which is a great benefit for consumers, these benefits can be classified into the following groups (Mateu, 2012). 


\section{Technical benefits}

When the distributed generation with renewable energy sources is implemented (photovoltaic panels, wind generators, hydraulic turbines, biomass, biogas, etc.), a profound change in the electrical system is created since this new model allows generation Modular and energy storage in small, medium and large scale.

a) Increase of the reliability in the supply of electrical energy, since the probabilities of failures by falls of the lines of high tension, are reduced when diminishing his percentage of use.

b) Connecting GD to a power system can improve voltage profile, power quality, and support for voltage stability.

c) It can help with demand during peak hours and in consumer management programs.

d) avoids the installed overcapacity, since an increase in the load would not be compensated through large centralized plants (fossil or renewable), since the small GD plants are more appropriate to respond to changes in demand, likewise, it can help in the reliability and continuity of the system, since the implementation of GD involves many generation sites and not just a large centralized generation.

e) Increases the quality of the electric wave through its convenient location and the characteristics of the energy injected into the network.

f) Reduces losses of electrical energy in both distribution and transport networks. The proper location of the GD systems reduces the power flow that entails the reduction of energy losses and the improvement of the stress profile. The reduction of losses in the transport and distribution of electricity increases the distribution capacity of the electricity grid. In our country, more than $10 \%$ of the electricity produced by the centralized system is lost in its transportation and distribution.

g) Intervenes in the stability of the system, since it can be used as a reserve supply of the necessary energy. It can provide various auxiliary services such as injection/consumption of reactive power to stabilize voltage, management of possible congestion through active power or participation in the adjustment and reserve markets.

h) Facilitates the integration of renewable generation, thanks to the implementation of two-way control and monitoring systems for consumption (smart grids.).

i) GD systems are modular and provide flexibility to the electrical distribution system. This implies a simple installation and in a short period of time. In addition, it provides a great advantage in the operation and maintenance of the system, as well as in the flexibility of its total capacity, increasing or decreasing the number of modules (variability in size and location).

\section{Economic benefits}

The DG can provide the necessary local load increases, installing them in specific locations, so they can reduce or avoid the construction of new transport and distribution lines, improve existing electrical systems and reduce the capacity of the systems of transport and distribution during the planning stage. By installing GD, the construction of conventional power plants is reduced. This reduction of costs, derived from the implementation of GD, allows reducing the price of electricity, energy production and imports, reducing investments in electrical infrastructure.

The decrease in operation and maintenance costs is achieved. The GD increases the life of the transformers and the equipment of the transport and distribution system, and facilitates fuel savings; the reduction of fuel costs is achieved due to the improvement of efficiency, in the case of cogeneration applications, using residual heat for heating, for cooling or to increase its efficiency by generating more electrical energy. Primary energy savings; it can be gradually coupled to the system and supply the exact demand that the customer needs; Increased safety and reliability for critical loads. This benefit is directly related to the increase in the quality of the electric wave. According to the different GD technologies, the types of energy and fuel resources used are diversified, therefore, there is no more interest in a certain type of fuel than in another; before large plants, much shorter installation times, lower investments and, therefore, lower financial risks are required, with the potential to reduce the global costs of electric service, participation of a large number of small and medium-

Sumba, E. F. S., Sumba, A. V. S., Castillo, G. A. L., \& Rodríguez, J. A. P. (2020). Impact of distributed generation in the electrical system of Ecuador. International Journal of Physical Sciences and Engineering, 4(1), 1-10. 
sized local businesses in business of power generation, since usually the generation, on a conventional scale, is limited to multinational foreign companies with large contribution capital.

\section{Environmental benefits}

The use of renewable GD systems progressively reduces the emission of pollutants into the atmosphere $\left(\mathrm{CO}_{2}\right)$. However, any GD system can influence the emission of pollutants due to the reduction in energy losses it causes. The low emission of pollution and high efficiency is a great benefit (Fernández, 2011).

The economic advantage of a decrease in transport networks and transformation centers implies a reduction in visual impact, better social acceptance, and great investments. As a result, the GD systems have a higher value-added option than the large producing plants, in addition to the areas for the large producing plants becoming increasingly scarce.

\section{Conclusion}

Through the investigation, the positive impact of the DG on the electricity sector of Ecuador can be verified, where the economic, technical and environmental benefits are highlighted, as it can also be shown that with the DG the electricity sector in the country and In all countries, it represents a strategic framework with all energy resources.

It is determined that Distributed Generation is very efficient for Ecuador since it refers to non-centralized sources of electricity generation that generate electricity in the same place where it is consumed, delivering energy ready to be consumed where it is needed, with what It saves all the cost of transporting electricity, infrastructure, maintenance, energy losses and, above all, protecting the interest of the consumer or end-user. The distribution of the sources is carried out anywhere in the world, where the medium is suitable for the renewable energy source to be implemented.

\section{Acknowledgments}

We are grateful to two anonymous reviewers for their valuable comments on the earlier version of this paper. 


\section{References}

Aguilera, JA (2012). "Energy sources and Kyoto protocol in the evolution of the Spanish electricity system., from Ph.D. dissertation, University: https://goo.gl/s8A6g3

Arconel. (2017). Regulations and regulations. https://goo.gl/RFuerV

Arconel. (2018). Annual and Multiannual Statistics of the Ecuadorian Electric Sector. https://www.regulacionelectrica.gob.ec/wp-content/uploads/downloads/2019/08/Estad\%C3\%

Barbosa, S.M. (2016). A competitive energy sources in a learning curves approach. from a proposed regulation that encourages renewed technologies: https://goo.gl/u6i8AN

Barreto, G. (2014). Methodology of application of distributed photovoltaic geração in baixa tensão we are underground reticulates of electric power distributors. https://goo.gl/W93aLG

Bayod, A., Mur, J., Bernal, j., Yusta, J., \& Dominguez, J. (2005). Definitions for Distributed. Higher Polytechnic Center, University of Zaragoza. Department of Electrical Engineering. https: // CD-6079\% 20 (1) unlocked.pdf

Belvinel, E.-T. G., Loor, G. A., Chilan, J. C. H., \& Gamez, M. R. (2018). Photovoltaic system implementation in baltra and puerto ayora islands. International Journal of Life Sciences,2(3), 20-27. https://doi.org/10.29332/ijls.v2n3.200

Conelec. (2013). The Electrification Master Plan 2013-2022. http://www.regulacionelectrica.gob.ec/wpcontent/uploads/downloads/2015/12/vol1-Resumen-Ejecutive-PME-2013-2022.pdf

Conelec. (2015). Regulation No. conelec - 009/06. https://www.regulacionelectrica.gob.ec/wpcontent/uploads/downloads/2015/12/CONELEC-PreciosRenovables4.pdf

Correa, P., González, D., \& Pacheco, J. (2016). Renewable energies and environment. Your legal regulation in Ecuador. University and Society, 179-183. http://scielo.sld.cu/pdf/rus/v8n3/rus24316.pdf

Fernandez, A. (2011.). "Impact of distributed generation on distribution system. From Department of Energy Technology, Aalborg University.

Flores, T.F. (2011). The Ecuadorian electricity sector in the last 20. repository.ausjal.org/handle/20.500.12032/419918

Forrester, J. (1969). Urban Dynamcis. file: /// C: /Users/HP/Downloads/76-1-370-2-10-20160726.pdf

Gallardo, C. (2013). Alternative Energy Class Slides.

Heras, I.S. (2005). Evaluation of the impact of distributed generation in distribution systems. https://riunet.upv.es/bitstream/handle/10251/1894/tesisUPV2271.pdf?sequence=1\&isAllowed=y

Hugo, C.H. (2014). Impact of generation distributed in distribution networks.

IEEE. (2006). http://www.dinel.us.es/wie/?q=node/1

Izquierdo, L.R. (2008). Modeling of complex systems through agent-based simulation and system dynamics.

Jiménez, J.D. (2012). Impact of distributed generation. Retrieved on November 7, 2019, from https: //DialnetImpactoDeLaGeneracionDistribudaEnEISistemaElectri-4239947.pdf

Macias, L., Vázquez, A., Rodríguez, M., \& Hidalgo, R. (2018). Renewable Energy Sources on the Change of Energy Matrix in Manabí Province. https://sloap.org/journals/index.php/irjeis/, 4 (4), 17 29.

Mantuano, J. L. S., Vera, M. J. C., \& Cedeño, E. N. (2019). Factors of photovoltaic system cost affect in Ecuador. International Research Journal of Engineering, IT \& Scientific Research, 5(6), 1-11. https://doi.org/10.21744/irjeis.v5n6.721

Mateu, C. (2012). Solar floor.https://suelosolar.com/newsolares/newsol.asp?id=7105\#comentar

Muñoz, J., Rojas, V., \& Barreto, R. (2017). INGENIUS Retrieved on November 30, 2018, from Incentive to distributed generation: https: //2108-Text\%20del\%20article-11702-4-10-20180109.pdf.

Rodríguez, M., Vázquez, A., Vélez, A., \& Saltos, W. (2018). Improvement of energy quality with photovoltaic systems in rural areas. Scientific Magazine, 33(3), 265-274.

Vázquez, A., Rodríguez, M., Saltos, W., Rodríguez, C., \& Cuenca, L. (2018). Energy, economic and environmental performance of a $3.4 \mathrm{KWp}$ Photovoltaic Power Plant in distributed generation mode (GD). Espacios Magazine, 39 (47), 34.

Vázquez, A., Rodríguez, M., Villacreses, C., \& Velez, A. (2019). Local Energy Development and Sustainability: The Ecuadorian University. Journal of Advanced Research in Dynamical and Control Systems, 11 (05 special Issue), 451-458.

Sumba, E. F. S., Sumba, A. V. S., Castillo, G. A. L., \& Rodríguez, J. A. P. (2020). Impact of distributed generation in the electrical system of Ecuador. International Journal of Physical Sciences and Engineering, 4(1), 1-10. 


\section{Biography of Authors}

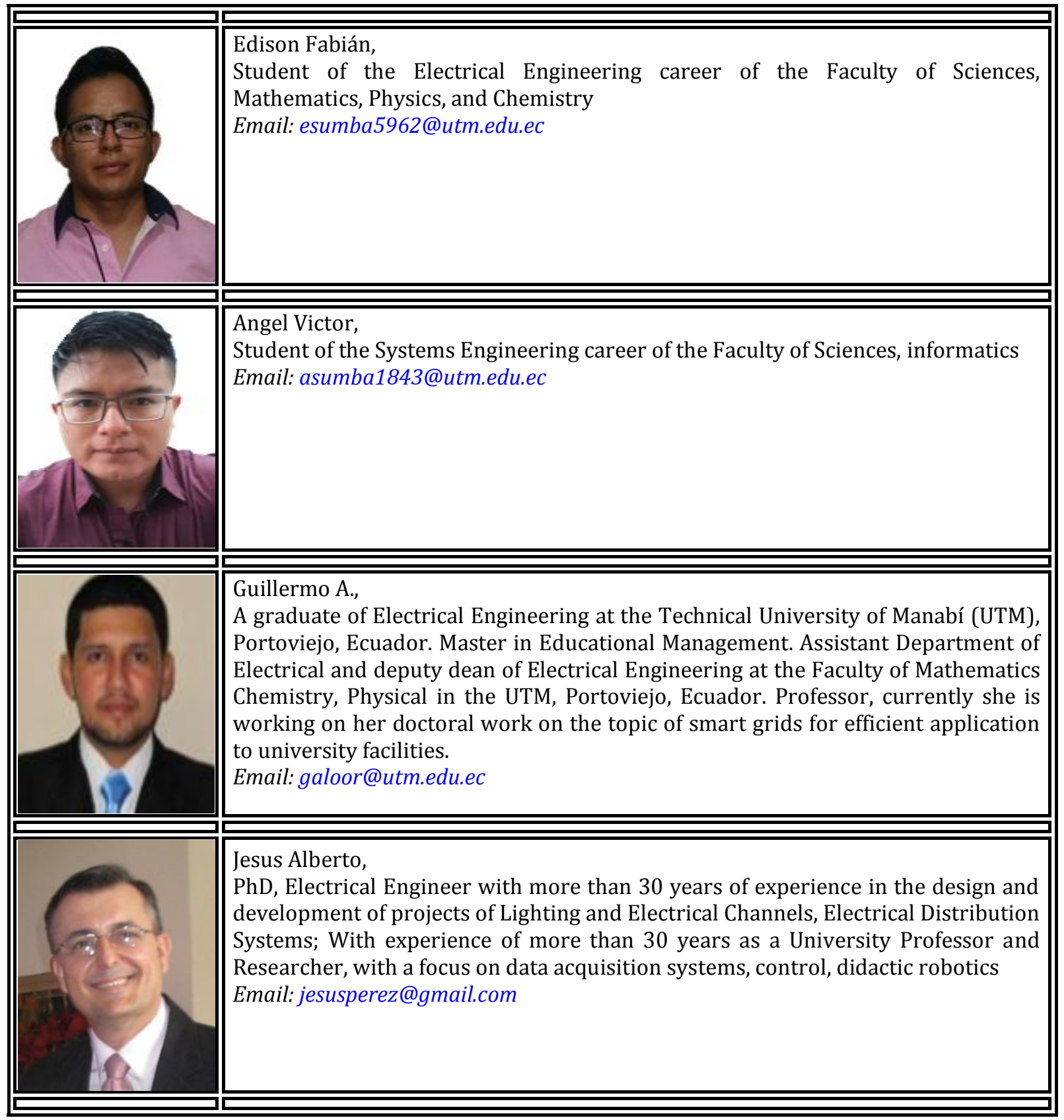

